\title{
Critérios anatomopatológicos para melanoma maligno cutâneo: análise qualitativa de sua eficácia e revisão da literatura
}

\author{
Anatomicopathological criteria for cutaneous malignant melanoma: qualitative analysis of efficacy and review \\ of the literature
}

Luiz Alberto Veronese'; Mariangela Esther Alencar Marques²

\begin{tabular}{l|l}
\multicolumn{1}{c|}{ Unitermos } & resumo \\
Melanoma & $\begin{array}{l}\text { São bastante conhecidos pelos patologistas o desafio e a dificuldade que algumas lesões melanocíticas } \\
\text { apresentam no momento de seu diagnóstico. A falta de uniformidade na maneira de aplicar os critérios } \\
\text { Diagnóstico diferencial }\end{array}$ \\
Nevo de Spitz & $\begin{array}{l}\text { diagnósticos é, sem dúvida, uma das causas principais dos altos índices de discordância descritos na } \\
\text { literatura. O objetivo deste trabalho é tentar diminuir esta discordância e, para isso, foram selecionados } \\
\text { Nevo displásico } 12 \text { critérios considerados mais importantes para o diagnóstico de melanoma: 1) tamanho; } 2 \text { ) simetria; } \\
\text { 3) delimitação lateral; 4) maturação; 5) disseminação pagetóide; 6) necrose/ulceração; 7) infiltrado } \\
\text { inflamatório; 8) regressão; 9) atipias celulares; 10) mitoses; 11) melanização; 12) proliferação de células } \\
\text { isoladas. Foram expostas as características de cada um deles e sua aplicação no diagnóstico dos mela- } \\
\text { nomas, lembrando sempre as possíveis exceções, onde estes critérios podem estar presentes em lesões } \\
\text { melanocíticas benignas. Posteriormente, em três tabelas, estabeleceu-se o diagnóstico diferencial entre } \\
\text { melanoma e três condições melanocíticas benignas que costumam apresentar maiores dificuldades no } \\
\text { diagnóstico diferencial. Como nenhum critério deve ser considerado isoladamente, a aplicação rigorosa } \\
\text { do conjunto de dados aqui fornecido pode ajudar substancialmente o patologista cirúrgico generalista } \\
\text { (não-especialista em lesões melanocíticas) a resolver alguns problemas na sua rotina diária. }\end{array}$
\end{tabular}

abstract

The challenge and the diagnostic difficulty imposed by some melanocytic lesions are well known by the pathologists. The lack of uniform diagnostic criteria is, without a doubt, one of the main causes for the high rates of disagreement described in literature. The aim of this report is to review twelve selected criteria in order to reduce diagnostic disagreement. These are: 1) size; 2) symmetry; 3) lateral delimitation; 4) maturation; 5) pagetoid spreading; 6) necrosis/ulceration; 7) inflammatory reaction; 8) regression; 9) cellular atypias; 10) mitosis; 11) melanization; 12) isolated cells proliferation. The characteristics of each one and their application in the diagnosis of melanomas were shown, always remembering possible exceptions in which these criteria might present in benign melanocytic lesions. Farther more, tables of differential diagnostic features are offered, for benign and malignant melanocytic lesions, using these histopathological criteria. As any criterion must not be considered by itself, the rigorous application of this data set here provided can substantially help the generalist surgical pathologist (non-specialist in melanocytic lesions) to solve some of the problems at his daily routine. key words

Melanoma

Differential diagnosis

Spitz nevus

Dysplastic nevus

\footnotetext{
1. Médico patologista do Instituto de Patologia de Araçatuba, SP; pós-graduando em nível de doutorado do Departamento de Patologia da Faculdade de Medicina de Botucatu, da Universidade Estadual Paulista (FMB/Unesp).

2. Professora-assistente; doutora do Departamento de Patologia da FMB/Unesp.

Trabalho realizado no Departamento de Patologia da FMB/Unesp.
} 


\section{Introdução}

São bem conhecidos dos médicos patologistas 0 desafio e a dificuldade que o exame anatomopatológico oferece no diagnóstico diferencial de algumas lesões melanocíticas. A interpretação subjetiva destes casos talvez seja o maior problema, que parece ainda maior quando deparamos com a realidade: o tratamento do paciente é baseado quase que exclusivamente no laudo anatomopatológico. Uma subvalorização da lesão pode custar a vida do paciente, enquanto a supervalorização leva a condutas radicais, muitas vezes mutiladoras, totalmente desnecessárias, sem contar com o estresse que esta pessoa carregará consigo. Além disso, a realidade da patologia de hoje é muito diferente da de 30 anos atrás. As campanhas de prevenção amplamente divulgadas pela mídia levam as pessoas a procurar os médicos mais precocemente por causa de suas lesões cutâneas, praticamente não mais existindo aqueles grandes tumores vistos no passado, em que a confirmação microscópica de malignidade era mera rotina. Atualmente examinamos lesões incipientes, portanto de mais difícil interpretação, sendo muitas delas microscopicamente semelhantes. Essa semelhança pode ser determinada pela imaturidade da lesão, que ainda não apresenta todos os seus caracteres fenotípicos bem visíveis, assim como uma criança não apresenta as características que terá quando adulta. Para que o diagnóstico seja feito são necessários conhecimento da morfologia dessas lesões, avaliação criteriosa das alterações presentes e bom senso. O objetivo desta revisão é expor alguns dos critérios existentes na literatura que consideramos mais importantes, revendo suas definições e comentando pontos relevantes de cada um, com a finalidade de diminuir a subjetividade, para que sejam utilizados com reprodutibilidade. Isoladamente, nenhum critério morfológico tem valor decisivo, havendo necessidade de uma análise conjunta dos critérios presentes em uma lesão que, aliada a bom senso, irá propiciar a elaboração de um diagnóstico seguro. O grande índice de desacordo de diagnósticos nesta área pelos patologistas experientes em lesões melanocíticas é fato bastante conhecido e discutido na literatura mundial $(2,19,22,23,33,43,46,53,58,68,80,83)$. A discordância deve-se, principalmente, a divergências na maneira de se aplicarem os critérios. Uma definição clara e funcional destes critérios deverá aumentar o índice de concordância. É importante salientar que, mesmo com a evolução da imunoistoquímica e da biologia molecular ${ }^{(6,9,10,12,13,16,28,40,45,55,67,74,78,81,85)}$, os critérios morfológicos pelo método de rotina ainda são a base do diagnóstico das lesões melanocíticas, justificando, portanto, as tentativas de aprimoramento neste sentido.

\section{Critérios anatomopatológicos para diagnóstico de melanoma cutâneo}

Foram selecionados 12 dos critérios mais utilizados na literatura mundial para estabelecer diagnóstico de malignidade versus benignidade das lesões melanocíticas. A Tabela 1 relaciona os critérios e seu respectivo comportamento nas lesões benignas e malignas.

\section{Tamanho da lesão}

Existe concordância na literatura mundial de que as lesões melanocíticas benignas costumam ter tamanho inferior a $10 \mathrm{~mm}$, enquanto os melanomas costumam ser maiores. Pode haver exceções a essa regra, com sobreposição de medidas em ambos os tipos de lesão. Também devemos levar em conta que a medida deverá ser efetuada durante o exame clínico, pois, se for executada na peça cirúrgica, haverá diferença para menos pela retração normal da pele após sua remoção e também pela fixação com formalina. Lesões melanocíticas com tamanho inferior a $4 \mathrm{~mm}$ e com alterações arquiteturais e/ou celulares devem ser cuidadosamente avaliadas, e o diagnóstico só deverá ser fornecido após correlação com os dados clínicos. $\mathrm{O}$ diagnóstico diferencial com lesões malignas pode apresentar dificuldades devido às características morfológicas que alguns nevos podem apresentar durante sua evolução temporal, incluindo atipias citológicas e alterações arquiteturais $(11,29,48,56,82)$.

\section{Simetria}

A lesão é considerada simétrica quando, dividida na sua porção central por um eixo imaginário vertical, as duas metades são muito semelhantes nos seus contornos, no tamanho e na forma dos ninhos de melanócitos, na distribuição dos componentes intraepiteliais e dérmicos e nas reações do hospedeiro, como a hiperplasia epitelial e o infiltrado inflamatório. As lesões benignas usualmente são simétricas, e as malignas, assimétricas (Figura 1). Existem exceções a essa regra, pois o melanoma nodular às vezes é simétrico, e alguns nevos podem ser assimétricos. Este critério foi bastante difundido e aceito, tendo, inclusive, sido considerado, no trabalho de Stolz ${ }^{(76)}$, um dos três mais importantes 


\section{Tabela 1 Caracteristicas das lesões benignas e malignas segundo o critério estudado}

\begin{tabular}{|c|c|c|}
\hline \multicolumn{3}{|l|}{ Lesão melanocítica } \\
\hline Critério & Lesão benigna & Lesão maligna \\
\hline 1. Tamanho & Pequeno $(<10 \mathrm{~mm})$ & Grande (> 10mm) \\
\hline 2. Simetria & Simétrica & Assimétrica \\
\hline 3. Delimitação lateral & Bem delimitada & Mal delimitada \\
\hline 4. Maturação & Presente (focal ou extensa) & Ausente \\
\hline 5. Disseminação pagetó ide & $\begin{array}{l}\text { Ausente; se presente, } \\
\text { focal e delimitada }\end{array}$ & Extensa \\
\hline 6. Necrose/ulceração & Ausente & Pode estar presente \\
\hline 7. Infiltrado inflamatório & Ausente ou discreto & Leve a intenso \\
\hline 8. Regressão & Ausente & Pode estar presente \\
\hline 9. Atipias celulares & Ausentes ou peculiares & Presentes/extensas \\
\hline profundas & Ausentes & Presentes \\
\hline atípicas & Ausentes & Presentes \\
\hline 11. Melanização da lesão & Regular e superficial & Irregular, podendo ser profunda \\
\hline 12. Proliferação de células isoladas & Ausente ou discreta & Presente e às vezes predominante \\
\hline
\end{tabular}

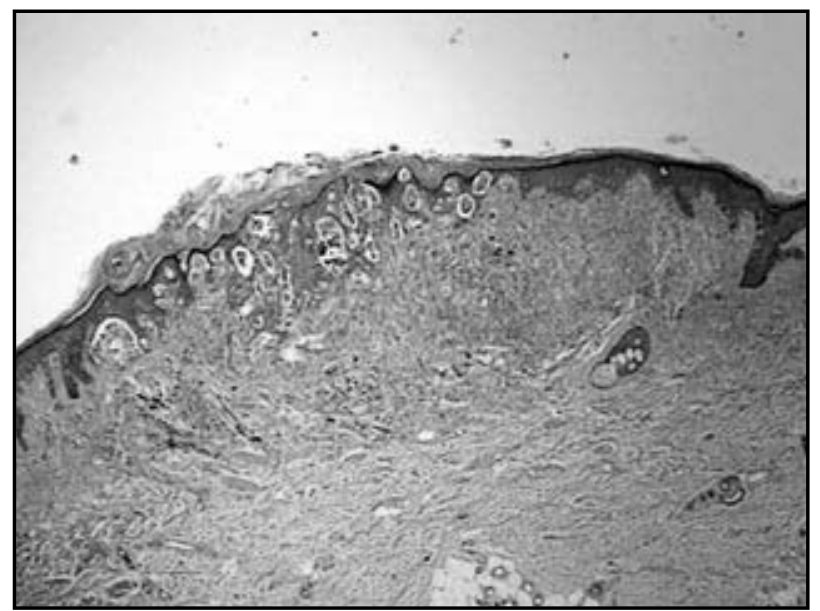

Figura 1 - Melanoma maligno exibindo assimetria (HE, 40x)

para o diagnóstico de melanoma (os outros dois foram atipia nuclear e o achado de células neoplásicas isoladas na epiderme/disseminação pagetóide). Até o início do século passado, o principal critério para diagnóstico de melanoma era o mesmo das outras neoplasias, ou seja, a presença de atipia celular; posteriormente, outros critérios foram sendo acrescentados. Além disso, foram descritos casos de neoplasias malignas cutâneas sem atipias (dermatofibrossarcomas, por exemplo) ao lado de neoplasias benignas cutâneas com marcadas atipias ${ }^{(77)}$. O nevo de Spitz é o exemplo clássico da lesão melanocítica de comportamento benigno e que pode ter intensas atipias celulares $^{(29,32,35,49)}$. Ackerman, em 1989(1), descreveu uma maneira de observação das lesões cutâneas que se ajustava, também, às proliferações melanocíticas. Trata-se da observação da silhueta ou do contorno da lesão em objetiva de pequeno aumento; aquelas que apresentarem simetria tendem a ser benignas, sendo o inverso também verdadeiro. Este critério tem sido bastante discutido, havendo controvérsias na literatura, incluindo argumentos contra seu uso na prática diária(${ }^{(60)}$. Em lesões como o nevo de Spitz, a verificação da silhueta pode ajudar bastante, uma vez que os outros critérios (atipias, mitoses, melanocitose pagetóide, etc.) às vezes não auxiliam na sua diferenciação com o melanoma ${ }^{(14,26,69)}$.

\section{Delimitação lateral}

Uma lesão melanocítica é considerada bem delimitada ou circunscrita quando as células lesionais intra-epidérmicas das suas bordas laterais estão predominantemente dispostas em ninhos (Figura 2). Habitualmente, as lesões que apresentam este padrão morfológico são benignas, porém existem lesões benignas que podem ser mal delimitadas, como o nevo lentiginoso (juncional ou composto), o nevo acral ${ }^{(70)}$ e alguns nevos displásicos ${ }^{(35)}$; nestas situações, a distribuição das células isoladas é uniforme e por toda a lesão, ao contrário dos melanomas, em que é irregular e focal ${ }^{(51)}$. 


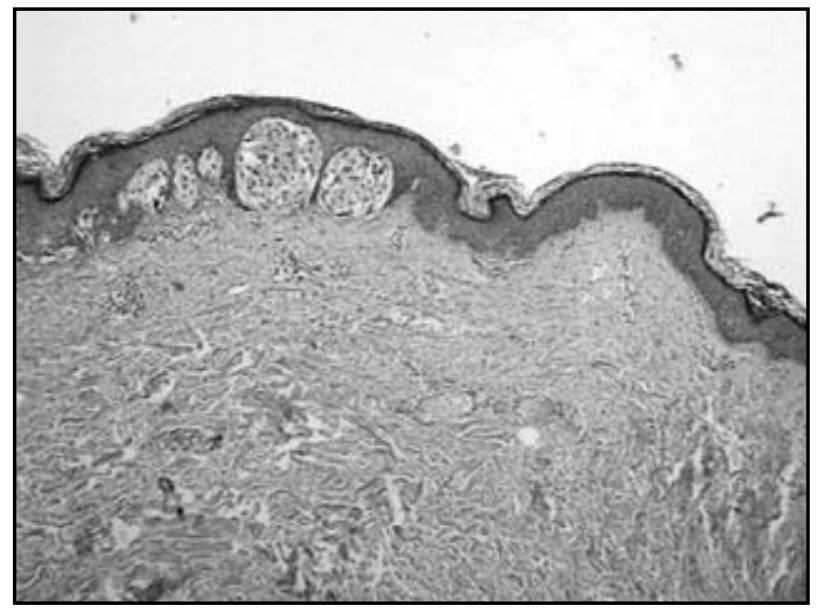

Figura 2 - Nevo juncional mostrando perfeita delimitação lateral da lesão (HE, 100x)

Quando as células isoladas predominam na borda do tumor, elas se estendem além do último ninho juncional, havendo dificuldade para se estabelecer uma clara demarcação de onde começa (ou termina) a lesão. A presença de células isoladas nas margens é responsável pela má delimitação observada na clínica, embora o espaçamento irregular dos ninhos também possa dar esta impressão. A presença de células isoladas nas margens da lesão favorece o diagnóstico de melanoma, principalmente se estiverem situadas acima da camada basal da epiderme. Okun ${ }^{(57)}$ questiona e condena a utilização desse critério (e de outros, como simetria da silhueta, acantose e corpos de Kamino) para o diagnóstico de melanoma, afirmando que seu uso em casos difíceis aumenta a possibilidade de erro.

\section{Maturação}

O termo maturação refere-se ao processo caracterizado histologicamente pela progressiva dissociação dos ninhos de melanócitos, com predominância de células isoladas e menores que as células superficiais, à medida que se aprofundam na derme, assemelhando-se a infiltrado inflamatório quando observadas em pequeno aumento. Esse fenômeno ocorre nas lesões benignas, tendo como exemplo clássico o nevo composto adquirido, mas estando presente também no nevo intradérmico e no nevo de Spitz ${ }^{(1,4,26,35,61)}$. No nevo composto, encontramos três tipos celulares na derme: 1) células do tipo A, situadas em contato com a epiderme, dispostas em ninhos de células coesas e pigmentadas, com citoplasma amplo, eosinofílico ou anfofílico e núcleos uniformes, com carioteca delicada e nucléolo pequeno e distinto; 2) células do tipo $B$, linfocitóides, situadas em posição intermediária na espessura da lesão, caracterizadas por citoplasma escasso, núcleos pequenos e hipercromáticos, quase não havendo síntese de melanina; 3 ) células do tipo C, situadas na porção profunda do nevo, arredondadas ou ligeiramente fusiformes, de aspecto fibroblástico ou schwannóide, isoladas ou em pequenos grupos, e sem melanina. Pela microscopia eletrônica observamos que as células A têm melanossomos abundantes, raros filamentos perinucleares e melanização variável. Já nas células $C$ há diminuição da área do núcleo, do diâmetro máximo do núcleo, da área da célula, do volume e do número das organelas citoplasmáticas (retículos endoplasmáticos liso e rugoso), bem como dos melanossomos (além da diminuição do número, estes se tornam menores), havendo paradoxalmente aumento no número e no volume das mitocôndrias, bem como dos filamentos perinucleares ${ }^{(36)}$. Se considerarmos que definimos maturação como o estágio terminal de diferenciação da célula, onde ela atinge a sua plenitude morfológica e funcional, então este termo pode ser considerado inadequado para esta situação; porém, como já é arraigado o seu uso, vamos utilizá-lo neste trabalho. Esforços têm sido feitos na tentativa de explicar o porquê destas alterações. Em 1988, Halaban ${ }^{(38)}$ estudou o fator de crescimento fibroblástico básico derivado dos ceratinócitos e concluiu que esta substância é um mitógeno natural para os melanócitos, e que a proximidade das células névicas com a epiderme poderia diferenciá-las mais do que as situadas à distância, na profundidade da lesão. O fenômeno da maturação normalmente está presente em lesões benignas, e sua ausência pode indicar possível malignidade. Deve ser ressaltado que este critério obviamente não se presta para auxílio diagnóstico em lesões intra-epidérmicas e também em lesões muito finas, onde fica muito difícil sua observação; neste último caso, o achado de mitoses em células lesionais na derme e de ninhos dérmicos maiores que o maior ninho epidérmico é importante no diagnóstico de invasão (fase vertical de crescimento). No nevo de Spitz clássico, talvez o diagnóstico diferencial mais difícil com melanoma, a maturação existe e obedece às mesmas regras dos nevos ordinários, embora haja exceções, o que torna ainda mais desafiante o seu diagnóstico ${ }^{(27)}$. No nevo de Spitz, as células lesionais maduras da base da lesão permeiam as fibras da derme reticular, formando filas indianas, o que difere frontalmente do padrão fascicular de invasão de melanomas ${ }^{(30)}$. Deve ser lembrado, ainda, que algumas lesões melanocíticas benignas não apresentam o fenômeno da maturação, como o nevo azul, o nevo combinado e alguns nevos penetrantes profundos. Em 
contrapartida, existem melanomas invasivos que mostram claramente alterações de diminuição do tamanho celular $^{(65)}$ na profundidade da lesão; também algumas metástases epidermotrópicas de melanomas malignos podem apresentar maturação ${ }^{(30,65)}$.

\section{Infiltração pagetóide da epiderme}

É definida como a presença de melanócitos isolados ou em grupos nas camadas superiores à basal da epiderme (Figura 3), sendo que estas células se assemelham àquelas encontradas na doença de Paget, com abundante citoplasma pálido e núcleos severamente atípicos ${ }^{(23)}$. Embora não esteja presente em todos os casos de melanoma, e também possa ser vista em algumas lesões melanocíticas benignas, é considerada um dos critérios mais importantes para o diagnóstico de melanoma. A infiltração pagetóide é mais evidente na fase radial de crescimento dos melanomas extensivo-superficiais, porém pode ser vista na epiderme sobre ou ao redor do componente invasivo de qualquer tipo de melanoma. Em 1995, alguns autores propuseram o termo melanocitose pagetóide (MP), estabelecendo alguns critérios e não considerando o aspecto morfológico destas células, ou seja, não havendo mais a necessidade de a célula neoplásica se assemelhar às células da doença de Paget ${ }^{(42)}$. A MP foi, então, definida como a extensão descontínua e ascendente de melanócitos para a epiderme superficial e que, embora seja bastante sugestiva de melanoma, pode aparecer em epiderme sobre um nevo com atividade proliferativa importante, como, por exemplo, no nevo congênito. Outras lesões benignas que podem exibir MP são os nevos acrais, os nevos recorrentes, os nevos juncionais ou compostos

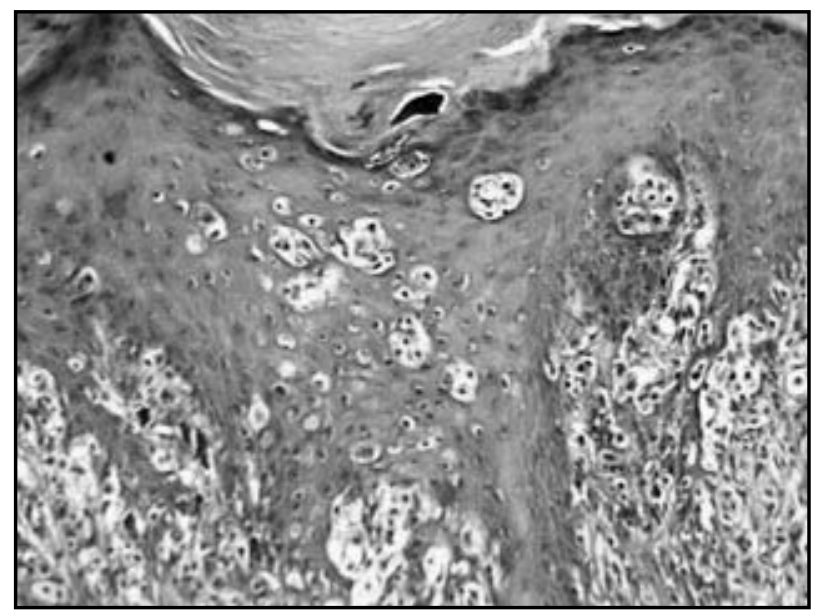

Figura 3 - Melanoma maligno extensivo superficial exibindo evidente disseminação pagetóide (HE, 200x) traumatizados, as lesões névicas do leito ungueal e o nevo de Spitz ${ }^{(51)}$, sendo que este último apresenta uma variante que se caracteriza justamente pela proeminente infiltração pagetóide da epiderme, daí sua denominação nevo de Spitz pagetóide ${ }^{(47)}$. Também existem situações em que células não-melanocíticas podem simular MP, como doença de Bowen pagetóide, doença de Paget, carcinoma sebáceo, carcinoma écrino ${ }^{(47)}$, micose fungóide, carcinoma de células de Merkel epidermotrópico, ceratinócitos de citoplasma claro (edema, depósito de glicogênio e retração citoplasmática por artefato de técnica), células inflamatórias e células de Langerhans ${ }^{(42)}$. Existem alguns achados dentro da própria MP que podem ajudar o patologista a tentar definir o comportamento biológico do tumor. Se a MP for extensa, difusa, densa, com extensão lateral e com atipia melanocítica proeminente, provavelmente estamos diante de um melanoma; se a MP for focal, escassa, sem extensão lateral e sem atipia, possivelmente a lesão é benigna ${ }^{(42)}$. Portanto a MP é um sinal de grande valia para o diagnóstico de malignidade que o patologista deve sempre pesquisar com atenção. Porém o diagnóstico final de melanoma somente poderá ser feito após estudo de outros parâmetros histopatológicos e correlação com a clínica.

\section{Necrose/ulceração}

A necrose é uma característica das lesões malignas, podendo ser mais ou menos extensa. Em uma revisão de 30 casos de melanoma maligno extensivo-superficial com metástases comprovadas, os autores encontraram focos de necrose em todas as lesões ${ }^{(63)}$. Em geral, a apoptose de células isoladas é bem mais freqüente que a necrose de grupos celulares nos melanomas. Os nevos quase nunca apresentam necrose, e, quando isto acontece, se faz pela forma de células isoladas e esparsas. A ulceração, quando excluída a possibilidade de origem traumática, também favorece malignidade, sendo em geral relacionada com o tamanho e a profundidade da lesão. Os melanomas nodulares e os acrais são os que mais apresentam ulceração, que é menos freqüente nos extensivo-superficiais e lentigos malignos ${ }^{(21)}$. Balch et al. ${ }^{(5)}$ demonstraram que a ulceração é um fator desfavorável no prognóstico dos melanomas, independentemente da sua espessura, e que a sobrevida diminui com o aumento da extensão da área ulcerada. A profundidade da úlcera não tem valor prognóstico. O mecanismo da ulceração não está bem elucidado; possivelmente 
está relacionado com a diminuição do suprimento sangüíneo pela rápida expansão tumoral na derme. Outros mecanismos possíveis para explicar ulceração seriam a fragilidade e a conseqüente rotura da epiderme devido à sua infiltração pelas células neoplásicas (disseminação pagetóide).

\section{Infiltrado inflamatório}

Os nevos adquiridos (com exceção do nevo displásico) raramente apresentam-se acompanhados de infiltrado inflamatório na derme. Já os melanomas mostram graus variados de infiltrado linfocitário, principalmente na fase radial de crescimento, situado ao redor de vasos do plexo superficial ou formando faixa na derme papilar (infiltrado liquenóide). Quando a lesão atinge a fase vertical de crescimento, a densidade do infiltrado tende a diminuir, podendo estar limitada à periferia do tumor (peritumoral). Menos freqüentemente, os linfócitos podem penetrar entre as células neoplásicas, caracterizando o infiltrado

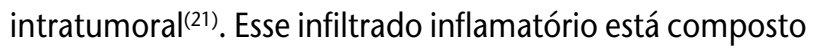
principalmente por linfócitos $T$, com predomínio das células T-helper/auxiliares sobre as células T-citotóxicas/ supressoras, e por células macrófagos-like, muitas das quais são células dendríticas derivadas das células de Langerhans. Linfócitos B são infreqüentes, embora alguns melanomas apresentem infiltrado inflamatório com populações quase puras de plasmócitos; as lesões com estas características tendem a ser avançadas (fase vertical) e ulceradas. A presença de plasmócitos costuma associarse a metástases e a pior prognóstico ${ }^{(72)}$. A intensidade do infiltrado inflamatório varia de leve a acentuada nos melanomas, sendo que maior densidade das células inflamatórias está relacionada com menor índice de recidivas. Quando os linfócitos penetram no tumor, o prognóstico é mais favorável(52). Segundo Clark ${ }^{(18)}$, a graduação da intensidade do infiltrado inflamatório deve ser mencionada no laudo do exame anatomopatológico. Na graduação utiliza-se o termo ausente para os casos em que não há infiltrado inflamatório e também naqueles em que o infiltrado é somente peritumoral (não infiltra o tumor). Quando as células inflamatórias permeiam as do tumor em toda a sua base e/ou estão esparsas entre as células neoplásicas, classifica-se como presente e ativo (brisk); se os linfócitos são vistos somente em um ou alguns focos da fase vertical de crescimento, chama-se de presente e inativo (nonbrisk). Deve ser lembrado que o componente linfocitário pode ser abundante em lesões melanocíticas com o fenômeno de halo. Nesta situação, o apagamento das características arquiteturais e as alterações degenerativas e regenerativas dos melanócitos podem levar à falsa impressão de atipia neoplásica, causando séria dificuldade no diagnóstico diferencial entre maligno e benigno. Qualquer lesão melanocítica pode ter reação de halo, porém as que mais causam problemas são os nevos de Spitz ${ }^{(41)}$ e os nevos displásicos. Alguns melanomas apresentam infiltrado inflamatório bastante intenso, dificultando a visualização das células neoplásicas na derme (Figura 4) e impedindo a realização de uma medida confiável da espessura da lesão (Breslow). Nestes casos, recomendamos que se coloque uma nota no laudo anatomopatológico relatando esta dificuldade e, também, propomos que se meça a espessura do infiltrado, não para servir como uma segunda medida de Breslow, mas para que o clínico possa saber, se houver células neoplásicas de permeio aos linfócitos, até que espessura elas podem estar localizadas. Deve ser ressaltado que, para a conduta terapêutica a ser tomada, somente o índice de Breslow, como descrito originalmente, deve ser considerado, ficando a segunda medida (do infiltrado inflamatório) como um parâmetro acessório para correlações futuras.

\section{Regressão tumoral}

Clinicamente, regressão de uma lesão melanocítica é definida como a redução parcial ou total do seu volume, restando, às vezes, áreas irregulares de despigmentação no local. Microscopicamente, a regressão pode ser definida como área de desaparecimento das células lesionais associada a inflamação e reparação na derme com melanoma bem definido nas adjacências, seja na epiderme ou

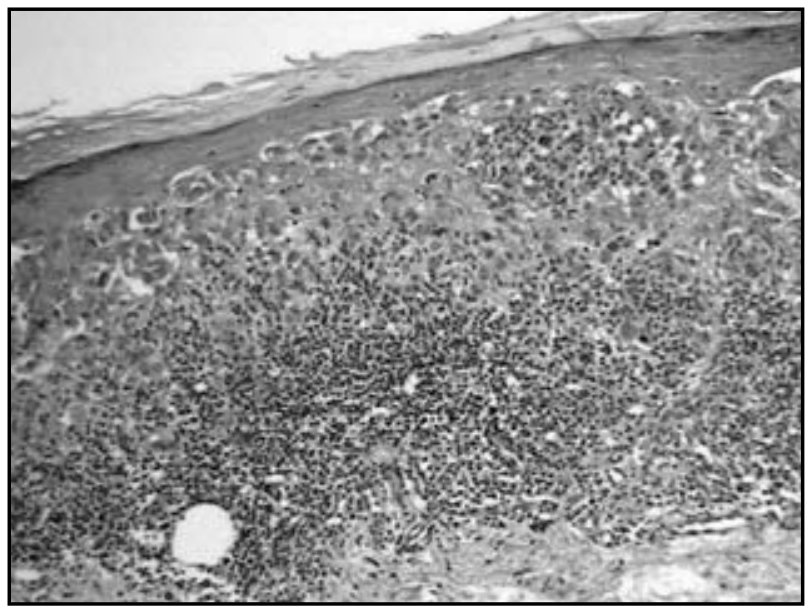

Figura 4 - Melanoma maligno contendo marcado infiltrado linfocitário na derme papilar (HE, 200x) 


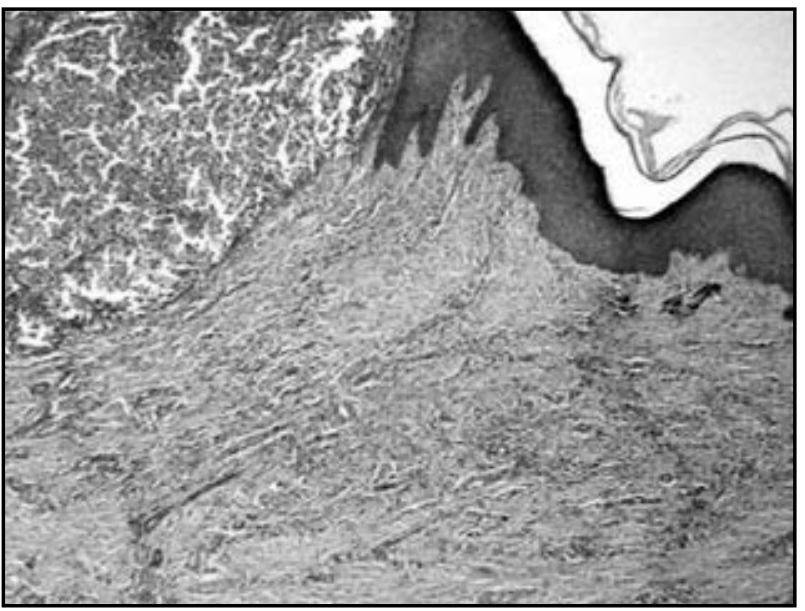

Figura 5 - Área de regressão tumoral tardia na derme (observar o melanoma no canto superior esquerdo) (HE, 40x)

na derme situada lateralmente (Figura 5). Este fenômeno imunológico é relativamente freqüente nos melanomas em fase radial de crescimento (melanomas microinvasivos), estando presente em cerca de metade dos casos nesta fase $^{(54)}$. A regressão também pode estar presente, embora muito menos freqüentemente, em lesões que atingiram a fase vertical de crescimento. $\mathrm{O}$ aparecimento de regressão em melanomas na fase radial de crescimento costuma ser seguido de progressão da lesão para a fase vertical. Nestes casos, o componente invasivo da fase vertical instala-se em região com aspecto de regressão prévia. A maneira mais segura de se fazer o diagnóstico de regressão em melanoma fino consiste no achado de um ou mais segmentos bem definidos dentro da lesão, onde há marcada redução ou ausência de melanócitos malignos na derme. Esta área deverá conter uma combinação variável de infiltrado linfocitário, fibrose, melanófagos, vasos neoformados e células de melanoma com alterações degenerativas. A epiderme que recobre a zona de regressão dérmica apresenta-se mais retificada e com marcada diminuição ou desaparecimento dos ninhos juncionais e das células melanocíticas isoladas(24), em comparação com a epiderme adjacente. Nem sempre as alterações encontradas são características; nestes casos, devemos descrevê-las como sugestivas de regressão. Existem ainda as fases de evolução da regressão, que são morfologicamente distintas. Na fase inicial, existe o infiltrado linfoistiocitário denso ao redor das células neoplásicas, por vezes formando rosetas que envolvem essas células; se o infiltrado for muito denso, as células tumorais tornam-se difíceis de ser individualizadas. Na fase intermediária, o infiltrado celular é menor que na fase anterior, e as células neoplásicas podem não estar mais presentes, predominando os fibroblastos, a deposição de colágeno e a neoformação vascular. Na fase tardia, a fibrose é evidente e extensa, há aumento do número de vasos sangüíneos, com ou sem melanófagos esparsos, e as células tumorais estão ausentes. Em vários trabalhos tentou-se relacionar a presença de regressão histológica com o prognóstico do paciente, tendo sido encontrados resultados contraditórios $^{(18,24,37,39,54,64,66,71,73)}$, porém a tendência hoje é aceitar que a regressão seja um parâmetro que pode indicar evolução desfavorável com possibilidade de metástase. É necessário enfatizar, no entanto, que somente a regressão completa (fase tardia, com fibrose e ausência de células de melanoma) tem valor prognóstico ${ }^{(27)}$ e apenas ela deve ser relatada no laudo final; a regressão parcial ou incompleta pode ser citada no laudo como nota ou comentário geral. Foram descritos casos de regressão total do melanoma primário com aparecimento de metástases regionais ${ }^{(71)}$. Um assunto pouco discutido na literatura, citado por Ronan ${ }^{(64)}$, é a questão da profundidade do tumor quando há regressão evidente no corte histológico. Podem existir melanomas em que a medida de sua espessura (Breslow) é inferior à medida da espessura da zona de regressão. Se considerarmos que na zona de regressão havia tumor, podemos fornecer, com esta medida, um dado de importância terapêutica que não pode ser subvalorizado. Por outro lado, não se pode ter certeza de que havia tumor em toda a espessura da zona de regressão; neste caso, a medida seria supervalorizada, alterando o prognóstico real. Assim sendo, consideramos que, nos casos em que isso acontecer, a espessura do tumor e a espessura da regressão devem ser citadas no laudo anatomopatológico. Essa alternativa poderia evitar possíveis surpresas em relação à sobrevida. Em trabalho recente, Massi et al. ${ }^{(52)}$ descreveram que, em melanomas finos $(<1,5 \mathrm{~mm})$, o parâmetro quantitativo $T+R$ (espessura do tumor mais espessura da regressão) é importante fator independente preditivo de progressão, ou seja, melanomas finos em pacientes com evolução desfavorável podem ser finos em virtude da regressão, podendo ter sido mais espessos no passado, como já havia sido citado por Gromet em $1978^{(37)}$.

\section{Atipias celulares}

Este é um dos critérios mais valorizados no diagnóstico dos melanomas, porém também é a causa de muita dificuldade na diferenciação de algumas lesões melanocíticas benignas e malignas, pois existem entidades benignas que podem exibir atipias evidentes. A definição de atipia celular 
não é muito clara, e está relacionada com o tamanho e a forma da célula, do núcleo e do nucléolo; a relação nucleocitoplasmática também é valorizada. Uma lesão melanocítica com atipias leves ou moderadas costuma ser benigna, enquanto a presença de atipias severas favorece 0 diagnóstico de melanoma. A atipia severa foi definida pelo Cancer Research Campaign Melanoma Pathology Panel(23) como apresentando núcleo grande, variável em tamanho e irregular na forma, cromatina grosseira com presença de espaços claros, nucléolo grande, às vezes múltiplo, e mitoses anormais, sendo que estas últimas são raras e nãoessenciais para esta definição. Em um estudo morfométrico e ultra-estrutural das lesões melanocíticas ${ }^{(75)}$, o tamanho do núcleo e a variação da área nuclear foram os melhores parâmetros na distinção entre nevos e melanomas. Em outro trabalho ${ }^{(76)}$, a atipia citológica foi considerada 0 critério mais sensível para o diagnóstico de melanoma ( $84 \%$ dos casos), seguida pela assimetria $(81,3 \%)$ e pela presença de células tumorais isoladas nas camadas superiores da epiderme (80,3\%). Jones ${ }^{(44)}$ pesquisou, entre 48 dermatopatologistas, os cinco critérios mais importantes para o diagnóstico de melanoma, e o mais citado deles foi a atipia citológica, seguida da infiltração pagetóide, da atividade mitótica com mitoses atípicas, da falta de maturação e da reação inflamatória dérmica (ordem decrescente de citações). Deve ser lembrado que os melanomas apresentam alteração no grau de atipia de uma lesão para outra, e também uma inconstância na proporção de células atípicas dentro de uma mesma lesão. Os melanócitos malignos apresentam aumento do tamanho do núcleo, com variação da sua forma, com contornos irregulares $\mathrm{e}$ com espessamento da carioteca; a cromatina costuma ser grosseira e o nucléolo, grande, eosinofílico e proeminente. As pseudo-inclusões nucleares, que na verdade são invaginações citoplasmáticas para dentro do núcleo, são também freqüentes nos melanomas, porém não são específicas desta lesão, podendo ser encontradas em lesões melanocíticas benignas. O citoplasma é abundante, eosinofílico e pode conter melanina granular ou finamente dividida (grãos de poeira). Às vezes existe retração citoplasmática ao redor do núcleo, formando um halo claro. O nevo de Spitz pode mostrar atipias importantes, além de mitoses, dificultando sua diferenciação com melanoma (Figura 6). Esta diferenciação deve ser baseada na associação de vários critérios; um deles, muito importante, é a chamada simetria citológica, que é a semelhança entre as células lesionais atípicas que se dispõem lado a lado, freqüente nos nevos de Spitz, enquanto as células do me- lanoma apresentam pleomorfismo mais acentuado, com variação de forma e tamanho e com presença de clones de células diferentes tanto do ponto de vista fenotípico como no comportamento biológico. Os clones caracterizam a fase de crescimento vertical dos melanomas com transformação intralesional das células malignas. Isto não deve ser confundido com a falta de maturação, que provoca a atipia uniforme dos melanomas, em que as células da porção superior da lesão são do mesmo tamanho que as da camada profunda. Nas situações de lesões spitzóides com atipias severas e disseminação pagetóide, em que o diferencial entre maligno e benigno pode ser tarefa impossível, a denominação proliferação melanocítica pagetóide é indicada pela NIH Consensus Conference ${ }^{(19)}$. O diagnóstico de lesão melanocítica atípica seguido de comentários também pode ser usado para esse tipo de lesão, em que a diferenciação entre maligno e benigno não pode ser feita com segurança.

\section{Mitoses}

Qualquer lesão melanocítica em fase de proliferação pode apresentar mitoses. De uma maneira geral, quando os nevos compostos ou intradérmicos (principalmente em crianças e mulheres grávidas) e o nevo de Spitz ${ }^{(50)}$ exibem mitoses, essas estão situadas no componente intra-epidérmico ou na derme superficial, e são em pequeno número. Raros nevos de Spitz em crianças podem exibir mitoses na porção profunda da lesão ${ }^{(62)}$; outras lesões que também podem ter mitoses profundas são o nevo azul, o nevo combinado e o nevo penetrante profundo. Como regra geral, mitose em célula situada profundamente em lesão de aspecto névico exige avaliação cuidadosa, alertando para a possibilidade de melanoma de desvio

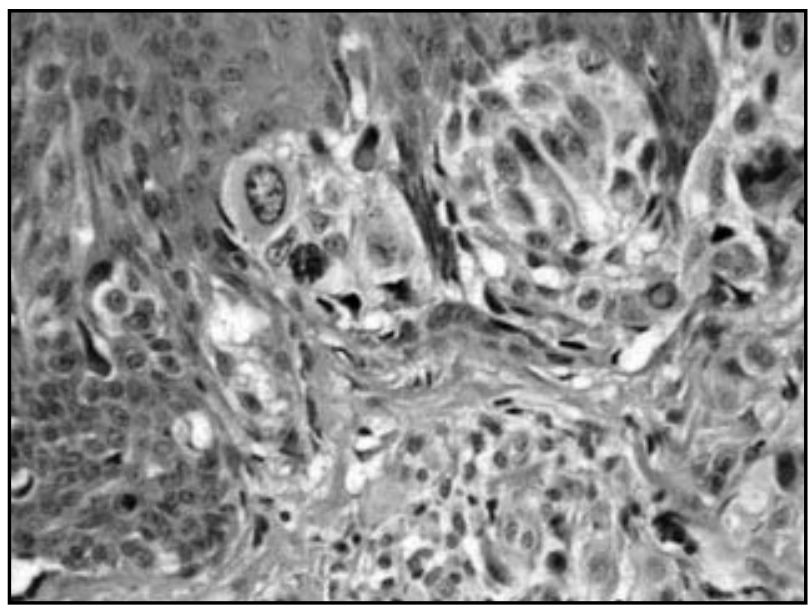

Figura 6 - Nevo de Spitz exibindo atipias celulares intensas (HE, 400x) 
mínimo. Alguns melanomas convencionais podem apresentar índice mitótico surpreendentemente baixo, porém, de uma maneira geral, as mitoses são mais freqüentes nos melanomas do que nos nevos. Mitoses atípicas deveriam representar malignidade nestas lesões, porém existem relatos de mitoses anormais em nevos de Spitz em crianças ${ }^{(3,62)}$. Apesar dessas exceções, a presença de mitoses profundas e de mitoses atípicas continua sendo um critério muito útil na avaliação desses tumores ${ }^{(76)}$. Nos laudos diagnósticos de melanoma deve ser mencionada a contagem de mitoses por $\mathrm{mm}^{2}$ da neoplasia invasiva. A contagem de mitoses só deve ser efetuada se houver fase vertical de crescimento, e mitoses intra-epidérmicas não devem ser consideradas ${ }^{(18)}$. Merece ser lembrado que o achado de mitose em células lesionais da derme papilar nos melanomas microinvasivos é indicativo de fase vertical de crescimento.

\section{Melanização da lesão}

A melanina é uma substância produzida pelo melanócito diferenciado. Assim sendo, seria de se esperar que o melanoma amelanótico ${ }^{(20)}$, como menos diferenciado, tivesse um comportamento biológico mais agressivo, porém isto não está comprovado. Talvez a dificuldade clínica de identificação do tumor cause um atraso no seu diagnóstico definitivo, levando à formação de tumores mais profundos e, portanto, de pior prognóstico. A distribuição da melanina nos tumores melanocíticos cutâneos primários pode ajudar na sua classificação. Nas lesões benignas, esperam-se a presença de melanina nas células do componente intra-epidérmico e nas células da derme superficial e a ausência do pigmento nas porções profundas. As exceções são o nevo congênito, o nevo

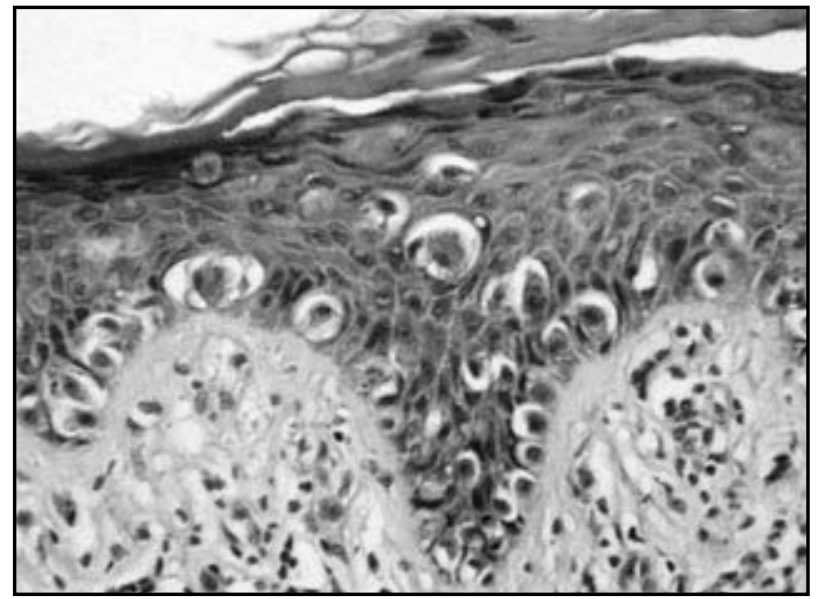

Figura 7 - Melanoma maligno extensivo superficial mostrando proliferação de células neoplásicas isoladas na camada basal (sem formação de ninhos) (HE, 400x) azul, o nevo combinado e o nevo penetrante profundo. Nos melanomas a distribuição da melanina é irregular, podendo estar presente nas células superficiais, nas profundas ou em ambas. Com algumas exceções (já citadas), a presença de melanina em células da porção profunda da lesão, especialmente quando disposta de maneira irregular, favorece o diagnóstico de melanoma.

\section{Proliferação de células isoladas na junção derme/epiderme}

Nas proliferações melanocíticas intra-epidérmicas, estas células podem se dispor em ninhos ou distribuirse isoladamente na junção derme/epiderme (Figura 7). Nos nevos lentiginosos (juncional ou composto), em alguns nevos displásicos e em alguns congênitos, encontramos células isoladas juncionais distribuídas regularmente por toda a extensão da lesão(51). As outras lesões melanocíticas benignas apresentam formação de ninhos. Nos melanomas, células isoladas juncionais são comuns, porém irregularmente dispersas, às vezes contíguas, intercalando-se com ninhos de tamanhos variados. Em melanomas pequenos do tipo extensivo-superficial, as células isoladas predominam sobre os ninhos; com o aumento do tamanho da lesão esta proporção se inverte ${ }^{(30)}$.

\section{Exemplos de diagnóstico diferencial}

Após seleção e definição, os critérios mais importantes para o diagnóstico anatomopatológico de melanoma serão utilizados no diagnóstico diferencial das lesões melanocíticas. Acreditamos que algumas das situações mais difíceis desta área da patologia sejam:

1. nevo de Spitz juncional ou composto superficial vs. melanoma maligno extensivo-superficial em fase radial de crescimento;

2. nevo de Spitz vs. melanoma nodular;

3. nevo displásico vs. melanoma maligno extensivo-superficial em fase radial de crescimento.

As lesões serão diagnosticadas segundo os critérios relacionados nas Tabelas 2, 3 e 4.

Na Tabela 4, além dos critérios mencionados, existem características inerentes ao nevo displásico que devem ser levadas em conta, como a fusão dos cones epiteliais, a irregularidade na disposição e no tamanho dos ninhos juncionais, as atipias celulares focais nas zonas de hiperplasia lentiginosa e a displasia epitelióide nos ninhos, a fibrose lamelar e a fibroplasia eosinofílica. 
Tabela 2

\section{Nevo de Spitz juncional vs. melanoma maligno extensivo-superficial em fase radial}

\begin{tabular}{|c|c|c|}
\hline Critério & $\begin{array}{c}\text { Nevo } \\
\text { de Spitz } \\
\text { juncional }\end{array}$ & $\begin{array}{l}\text { Melanoma maligno } \\
\text { extensivo-superficial em fase } \\
\text { radial de crescimento }\end{array}$ \\
\hline 1. Tamanho & Muito pequeno $(<3 \mathrm{~mm})$ & Geralmente grande (>10mm) \\
\hline 2. Simetria & Simétrico & Assimétrico \\
\hline 3. Delimitação lateral & Bem delimitado & Mal delimitado \\
\hline 4. Maturação & Não-avaliável & Não-avaliável \\
\hline 5. Disseminação pagetóide & Raramente presente e focal & Evidente \\
\hline 6. Necrose/ulceração & Ausente & Ausente \\
\hline 7. Infiltrado inflamatório & Discreto ou ausente & Variável (leve a intenso) \\
\hline 8. Regressão & Ausente & Pode haver \\
\hline 9. Atipias celulares & Discretas & Marcadas \\
\hline 10. Mitoses & Raras & Variávéis (poucas a muitas) \\
\hline 11. Melanização & Regular & Irregular \\
\hline $\begin{array}{l}\text { 12. Proliferação de } \\
\text { células isoladas }\end{array}$ & $\begin{array}{l}\text { Presente, porém com } \\
\text { predomínio de ninhos }\end{array}$ & Presente e irregular \\
\hline
\end{tabular}

\section{Tabela 3 Nevo de Spitz vs. melanoma nodular}

\begin{tabular}{lcc}
\hline Critério & Nevo de Spitz & Melanoma nodular \\
$\begin{array}{l}\text { 1. Tamanho } \\
\text { 2. Simetria }\end{array}$ & Simétrico & Usualmente $>10 \mathrm{~mm}$ \\
3. Delimitação lateral & Bem delimitado & Assimétrico, podendo ser simétrico \\
4. Maturação & Presente & Mal delimitado \\
5. Disseminação pagetóide & Ausente (raramente presente e focal) & Ausente \\
6. Necrose/ulceração & Ausente & Presente \\
7. Infiltrado inflamatório & Leve e perivascular & Pode estar presente \\
8. Regressão & Ausente & Variável \\
9. Atipias celulares & Discretas e peculiares & Pode estar presente \\
10. Mitoses & Raras e geralmente superficiais & Variávéis, podendo ser profundas \\
11. Melanização & Discreta e regular & Variável, irregular e, às vezes, profunda \\
12. Proliferação de & Presente, regular & Pode estar presente \\
células isoladas & e em grau leve & \\
\hline
\end{tabular}




\section{Tabela 4 Nevo displásico juncional vs. melanoma maligno extensivo-superficial em fase radial}

\begin{tabular}{|c|c|c|}
\hline Critério & $\begin{array}{c}\text { Nevo } \\
\text { displásico juncional }\end{array}$ & $\begin{array}{c}\text { Melanoma maligno } \\
\text { extensivo-superficial em } \\
\text { fase radial de crescimento }\end{array}$ \\
\hline 1. Tamanho & Variável (geralmente < 10mm) & Variável (geralmente $>10 \mathrm{~mm}$ ) \\
\hline 2. Simetria & Geralmente assimétrico & Assimétrico \\
\hline 3. Delimitação lateral & Pode ser mal delimitado & Mal delimitado \\
\hline 4. Maturação & Não-avaliável & Não-avaliável \\
\hline 5. Disseminação pagetóide & Ausente & Evidente \\
\hline 6. Necrose/ulceração & Ausente & Ausente \\
\hline 7. Infiltrado inflamatório & Variável, geralmente perivascular & Variável, geralmente liquenóide \\
\hline 8. Regressão & Muito rara & Pode estar presente \\
\hline 9. Atipias celulares & Variáveis & Marcadas \\
\hline 10. Mitoses & Raras & Presentes \\
\hline 11. Melanização & Geralmente escassa & Variável \\
\hline 12. Proliferação de & Presente & Presente \\
\hline
\end{tabular}

\section{Conclusões}

A utilização destes critérios de maneira uniforme e objetiva pode, na maioria das vezes, levar à conclusão diagnóstica, mesmo em casos muito difíceis. Naturalmente, em alguns casos a facilidade é maior do que em outros, porém a intenção deste trabalho é propor o uso sistemático destes critérios, cuja aplicação permita reduzir a subjetividade e aumentar a reprodutibilidade para a realização de diagnósticos objetivos e seguros em lesões melanocíticas.

\section{Agradecimentos}

Os autores agradecem a preciosa colaboração da dra. Catarina Schaletich, de Ribeirão Preto, cujas idéias e sugestões foram de grande valia para a confecção deste trabalho.

\section{Referências}

I. ACKERMAN, A. B. Differentiation of benign from malignant neoplasms by silhouette. Am J Dermatopathol, v. I I, n. 4, p. 297-300, 1989

2. ACKERMAN, A. B. Discordance among expert pathologists in diagnosis of melanocytic neoplasms. Hum Pathol, v. I I, p. || | 5-6, 1996.

3. ACKERMAN,A. B.; JACOBSON, M.; VITALE, P. Clues to diagnosis in dermatopathology. Chicago: ASCP Press, 3 volumes, 1991.

4. ACKERMAN, A. B. Malignant melanoma: a unifying concept. Hum Pathol, v. II, n. 6, p. 591-5, 1980.

5. BALCH, C. M. et al.The prognostic significance of ulceration of cutaneous melanoma. Cancer, v. 45, p. 3012-7, 1980.
6. BANERJEE, S. S.; HARRIS, M. Morphological and immunophenotypic variations in malignant melanoma. Histopathology, v. 36, n. 5, p. 387-402, 2000.

7. BARNHILL, R. L. et al. Cutaneous melanoma and atypical Spitz tumors in childhood. Cancer, v. 76, n. 10, p. 1833-45, 1995.

8. BARNHILL, R. L. Malignant melanoma, dysplastic nevi, and Spitz tumors: histological classification and characteristics. Clin Plast Surg, v. 27, n. 3, p. 331-60, 2000.

9. BASTIAN, B. C. et al. Molecular cytogenetic analysis of Spitz nevus shows clear differences to melanoma. J Invest Dermatol, v. I I3, n. 6, p. 1065-9, 1999.

10. BJORNHAGEN, V. et al. Morphometric, DNA, and proliferating cell nuclear antigen measurements in benign 
melanocytic lesions and cutaneous malignant melanoma. Am J Dermatopathol, v. 16, p. 615-23, 1994.

I I. BLESSING, K. Benign atypical naevi: diagnosis difficulties and continued controversy. Histopathology, v. 34, p. 189-98, 1999.

12. BLESSING, K.; SANDERS, D. S. A.; GRANT, J. J. H. Comparison of immunohistochemical staining of the novel antibody Melan-A with SI00 protein and HMB-45 in malignant melanoma and melanoma variants. Histopathology, v. 32, p. 139-46, 1998

13. BUSAM, K. J. et al. Expression of Melan-A (Mart-I) in benign melanocytic naevi and primary cutaneous malignant melanoma. Am J Surg Pathol, v. 22, p. 976-82, 1998.

I4. CASSO, E. M.; GRIN-JORGENSEN, C. M.; GRANT-KELS, J. M. Spitz Nevi. J Am Acad Dermatol, v. 27, p. 901-13, 1992.

15. CERRONI, L.; KERL, H. Tutorial on melanocytic lesions. Am J Dermatopathol, v. 23, n. 3, p. 237-4I, 2001.

16. CERRONI, L.; SOYER, H. P.; Kerl, H. Bcl-2 protein expression in cutaneous malignant melanoma and benign melanocytic nevi. Am J Dermatopathol, v. 17, n. I, p. 7- I I, 1995.

17. CLARK, W. H. et al. A study of tumor progression: the precursor lesions of superficial spreading and nodular melanoma. Hum Pathol, v. I 5, p. I 147-65, 1984.

18. CLARK, W. H. et al. Model predicting survival in stage I melanoma based on tumor progression. J Natl Cancer Inst, v. 81, p. 1893-904, 1989.

19. CLARK, W. H. et al. NIH Consensus Conference. Early melanoma: histologic terms. Am J Dermatopathol, v. I3, n. 6, p. 579-82, 1991.

20. CLARK,W. H. et al. The histogenesis and biologic behavior of primary human malignant melanomas of the skin. Cancer Research, v. 29, n. 29, p. 705-27, 1969.

21. COCHRAN,A.J. et al. Melanocytic tumors: a guide to diagnosis. Biopsy Interpretation Series. Lippincott-Raven, 1997.

22. COOK, M. G. Diagnostic discord with melanoma. J Pathol, v. 182, p. 247-9, 1997

23. COOK, M. G. et al. The evaluation of diagnostic and prognostic criteria and the terminology of thin cutaneous malignant melanoma by the CRC Melanoma Pathology Panel. Histopathology, v. 28, p. 497-5 I2, 1996.

24. COOPER, P. H.; WANEBO, J. H.; HAGAR, R. W. Regression in thin malignant melanomas. Microscopic diagnosis and prognostic importance. Arch Dermatol, v. I21, p. I 127-31, 1985.

25. CROTTY, K. A. et al. Malignant melanoma in childhood: a clinicopathologic study of 13 cases and comparison with Spitz nevi. World J Surg, v. 16, n. 2, p. 179-85, 1992.

26. CROTTY, K. A. Spitz nevus: histological features and distinction from malignant melanoma. Austral J Dermatol, v. 38, suppl. I, p. 49-53, 1997.

27. CROWSON, A. N.; MAGRO, C. M.; MIHM, M. C. The melanocytic proliferations: a comprehensive textbook of pigmented lesions. Wiley-Liss, 200 I.
28. DE WIT, P. E. J. et al. Increasing epidermal growth factor receptor expression in human melanocytic tumor progression. J Invest Dermatol, v. 99, p. 162-73, 1992.

29. EDWARDS, S. L.; BLESSING, K. Problematic pigmented lesions: approach to diagnosis. J Clin Pathol, v. 53, n. 6, p. 409- | 8, 2000.

30. ELDER, D. E.; MURPHY, G. F. Melanocytic tumors of the skin. Atlas of Tumor Pathology. $3^{\text {a }}$ série. AFIP, 1990.

31. ELDER, D. E. et al. Neoplastic progression and prognosis in melanoma. Semin Cutan Med Surg, v. 15, n. 4, p. 336-48, 1996.

32. FABRIZI, G.; MASSI, G. Polypoid Spitz nevus: the benign counterpart of polypoid malignant melanoma. $\mathrm{Br} J$ Dermatol, v. 22, p. 128-32, 2000.

33. FARMER, E. R.; GONIN, R.; HANA, M. P. Discordance in the histopathologic diagnosis of melanoma and melanocytic nevi between experts. Hum Pathol, v. 27, p. 528-31, 1996.

34. FERREIRA, C. M. M.; PIÑEIRO-MACIEIRA, J. P.; COELHO, J. M. C. O. Análise imunoistopatológica, clínica e evolutiva dos melanomas. An Bras Dermatol, v. 72, n. 2, p. 1 17-26, 1997.

35. GARCÍA, S. Pseudomalignidades névicas. Arch Argent Dermatol, v. 40, n. 4, p. 275-87.

36. GOOVAERTS, G.; BUYSSENS, N. Nevus cell maturation or atrophy? Am J Dermatopathol, v. I0, n. I, p. 20-7, 1988.

37. GROMET, M. A.; EPSTEIN, W. L.; BLOIS, M. S. The regressing thin malignant melanoma. A distinctive lesion with metastatic potential. Cancer, v. 42, p. 2282-92, 1978.

38. HALABAN, R. et al. Basic fibroblastic growth factor from human keratinocytes is a natural mitogen for melanocytes. J Cell Biol, v. 107, p. 16I I-9, 1988.

39. HALPERN, A. C.; SCHUCHTER, L. M. Prognostic models in melanoma. Semin Oncol, v. 24, suppl. 4, p. 2-7, 1997.

40. HARMSE, J. L.; EVANS, A. T. Proliferation and apoptotic indices in Spitz lesions. J Pathol, v. 189, p. 26A, 1999.

4I. HARVELL, J. D.; MEEHAN, S. A.; LEBOIT, P. E. Spitz nevi with halo reaction: a histopathologic study of 17 cases. J Cutan Pathol, v. 24, n. 10, p. 61 I-9, 1997.

42. HAUPT, H. M.; STERN, J. B. Pagetoid melanocytosis: histological features in benign and malignant lesions. Am J Pathol, v. 19, n. 7, p. 792-7, 1995.

43. Jackson, R. Malignant melanoma: a review of 75 malpractice cases. Int J Dermatol, v. 36, p. 497-8, 1997.

44. JONES, R. E. What are your five most important histological criteria for the diagnosis of malignant melanoma ? Am J Dermatopathol, v. 6, p. 337-9, 1984.

45. KANTER-LEWENSOHN, L. et al. Immunohistochemical markers for distinguishing Spitz nevi from malignant melanomas. Mod Pathol, v. 10, n. 9, p. 917-20, 1997.

46. KEEMPF, W. et al. Experts and gold standards in dermatopathology. Am J Dermatopathol, v. 20, p. 478-82, 1998.

47. KLAUS, J. B.; BARNHILL, R. L. Pagetoid Spitz nevus: intraepidermal Spitz tumor with proeminent pagetoid spread. Am J Surg Pathol, v. 19, n. 9, p. 1061-7, 1995. 
48. KLEIN, L. J.; BARR, R. L. Histologic atypia in clinically benign nevi: a propective study. J Am Acad Dermatol, v. 22, p. 27582, 1990.

49. KELLEY, S.W.; COCKERELL, C. J. Sentinel lymph node biopsy as an adjunct to management of histologically difficult to diagnose melanocytic lesions: a proposal. J Am Acad Dermatol, v. 42, n. 3, p. 527-30, 2000.

50. MAGAÑA, M. Nevos melanocíticos en la infancia. Bol Med Hosp Infant Mex, v. 57, n. 5, p. 280-91, 2000.

5I. MAIZE, J. C. et al. Neoplasms of melanocytes. In: Cutaneous pathology. Philadelphia: Churchill-Livingstone, 1998. p. $64|-7| 4$

52. MASSI, G. et al. Thin cutaneous malignant melanoma $(<$ or $=1,5 \mathrm{~mm}$ ): identification of risk factors indicative of progression. Cancer, v. 85, n. 5, p. 1067-76, 1999.

53. MCDERMOTT, N. C. et al. Identification of vertical growth phase in malignant melanoma. Am J Clin Pathol, v. I I0, p. 753-7, 1998

54. MCGOVERN, V. J.; SHAW, H. M.; MILTON, G. W. Prognosis in patients with thin malignant melanoma: influence of regression. Histopathology, v. 7, p. 673-80, 1983.

55. MCNUTT, N. S. et al. Nevoid malignant melanoma: morphologic patterns and immunohistochemical reactivity. J Cutan Pathol, v. 22, p. 502-17, 1995.

56. OKAMURA, J. M.; BARR, R. J.; CANTOS, K. A. Benign atypical juncional melanocytic hiperplasia associated with intradermal nevi: a common finding that may be confused with melanoma in situ. Mod Pathol, v. 13, n. 8 , p. 158-62, 2000

57. OKUN, M. R. Histological demarcation of lateral borders: an unsupportable criterion for distinguishing malignant melanoma from Spitz nevus and compound nevus. Histopathology, v. 33, n. 2, p. 158-62, 1998.

58. OKUM, M. R.; KIRKHAM, N.; SLATER, D. N. What criteria reliably distinguish melanoma from benign melanocytic lesions? Histopathology, v. 37, p. 464-72, 2000.

59. OKUN, M. R. Melanoma resembling spindle and epithelioid nevus. Arch Dermatol, v. I I5, n. 12, p. 1416-20, 1979.

60. OKUN, M. R. Silhouette simmetry: an unsupportable histologic criterion for distinguishing Spitz nevi and compound nevi from malignant melanoma. Arch Pathol Lab Med, v. I 2 I, n. I, p. 48-53, 1997.

6I. PANIAGO-PEREIRA, C.; MAIZE, J. C.; ACKERMAN, A. B. Nevus of large spindle and/or epithelioid cells (Spitz nevus). Arch Dermatol, v. I | 4, p. I8 I I-23, 1978.

62. PETERS, M. S.; GOELLNER, J. R. Spitz naevi and malignant melanomas of childhood and adolescence. Histopathology, v. 10, p. 1289-302, 1986.

63. PRICE, N. M.; RYWLIN, A. M.; ACKERMAN, A. B. Histological criteria for the diagnosis of superficial spreading malignant melanoma: formulated on the basis of proven metastatic lesions. Cancer, v. 38, p. 2434-4I, 1976.

64. RONAN, S. G. et al. Thin malignant melanomas with regression and metastases. Arch Dermatol, v. 123, p. 1325-30, 1987.
65. RUHOY, S. M. et al. Malignant melanoma with paradoxical maturation. Am J Surg Pathol, v. 24, n. 12, p. 1600-14, 2000.

66. SAGEBIEL, R. Regression and others factors of prognostic interest in malignant melanoma. Arch Dermatol, v. 121, p. $1125-6,1985$.

67. SCHAUMBURG-LEVER, G. et al. Melanocytes in nevi and melanomas synthesize basement membrane and basement membrane-like material: an immunohistochemical and electron microscopic study including immunoelectron microscopy. J Cutan Pathol, v. 27, n. 2, p. 67-75, 2000.

68. SCHMOECKEL, C. How consistent are dermatopathologists in reading early malignant melanomas and lesions "precursor" to them? Am J Dermatopathol, v. 6, p. 13-24, 1984.

69. SHIMEK, C. M.; GOLITZ, L. E. The golden anniversary of the Spitz nevus. Arch Dermatol, v. I35, p. 333-5, 1999.

70. SIGNORETTI, S. et al. Melanocytic nevi of palms and soles: a histologic study according to the plane of section. Am J Surg Pathol, v. 23, p. 283-7, 1999.

7I. SMITH, J. L.; STEHLIN, J. S. Spontaneous regression of primary malignant melanomas with regional metastases. Cancer, v. II. p. 1399-4I5, 1985.

72. SMITH, K. et al. Spindle cell and epithelioid cell nevi with atypia and metastases (malignant Spitz nevus). Am J Surg Pathol, v. 13, p. 931-9, 1989.

73. SONDERGAARD, K; HOU-JENSEN, K. Partial regression in the thin primary cutaneous malignant melanomas clinical stage I. Virchow's Arch (Pathol Anat), v. 408, p. 24I-7, 1985.

74. SPRECHER, E. et al. Apoptosis, fas and fas-ligand expression in melanocytic tumors. J Cutan Pathol, v. 26, p. 72-7, 1999.

75. STOLZ,W. et al. Morphometric and ultrastructural analyses of melanocytes, nevus cells, and melanoma cells. Arch Dermatol Res, v. 279, p. 167-72, 1987.

76. STOLZ,W. et al. Semiquantitativeanalysis of histologic criteria in thin melanomas. J Am Acad Dermatol, v. 20, p. I I 15-20, 1989.

77. TAMADA, S.;ACKERMAN,A. B. Dermatofibroma with monster cells. Am J Dermatopathol, v. 9, n. 5, p. 380-7, 1987.

78. THORNE, G. E.; MOTTAZ, J. H.; ZELICKSON, A. S. Tyrosinase activity in dermal nevus cells. Arch Dermatol, v. 104, p. 619-24, 1971.

79. TOUSSAINT, S.; KAMINO, H. Dysplastic changes in different types of melanocytic nevi. A unifying concept. / Cutan Pathol, v. 26, p. 84-90, 1999.

80. TROXEL, D. B. Diagnosis errors in surgical pathology uncovered by a review of malpractice claims. Part IV, Melanoma. Int J Surg Pathol, v. 9, n. I, p. 61-3, 200 I.

8I. TU, P.; MIYAUCHI, S.; MIKI, Y. Proliferative activities in Spitz nevus compared with melanocytic nevus and malignant melanoma using expression of PCNA/cyclin and mitotic rate. Am J Dermatopathol, v. I5, n. 4, p. 31 I-4, 1993.

82. URSO, C. Atypical histological features in melanocytic nevi. Am J Dermapathol, v. 22, n. 5, p. 39I-6, 2000.

83. VEENHUIZEN, K. C. W.; DE WIT, P. E. J.; MOOI, W. J. Quality assessment by expert opinion in melanoma pathology: 
experience of the Pathology Panel of the Dutch Melanoma Working Party.J Pathol, v. I 82, p. 266-72, 1997.

84.WALSH, N. et al. Spitz nevus versus spitzoid malignant melanoma: an evaluation of the current distinguishing histopatologic criteria. Hum Pathol, v. 28, n. I0, p. I I05-12, 1998.
85. WANG, Y. et al. Molecular analysis of melanoma precursor lesions. Cell Growth Differ, v. 7, p. 1733-40, 1996.

86. WEEDON, D.; LITTLE, J. H. Spindle and epithelioid cell nevi in children and adults. Cancer, v. 40, p. 217-25, 1977. 